\title{
HEPATITIS C: A NEW FUTURE EVERYDAY
}

\author{
SALIMUR RAHMAN
}

\begin{abstract}
:
Hepatitis $\mathrm{C}(\mathrm{HCV})$ is one of the most important cause of liver disease throughout the world, having the potentiality to develop cirrhosis and hepatocellular carcinoma with the passage of time. Recent advances in the management of HCV infection have brought this healthcare burden under limelight. With ongoing research in this field, the future seems to be more promising in the management of $H C V$ infection that has been bothering humanity for decades.
\end{abstract}

Key words: Hepatitis C, HCV genotype, HCV treatment, Peg-IFN, DAA.

Received: 03 December 2015

Accepted: 09 June 2016

\section{Introduction:}

Hepatitis C Infection is a major healthcare concern, affecting more than 185 million individuals worldwide (2.8\% of world population), with prevalence ranging from $0.5 \%$ to nearly $18 \%$ in countries burdened with this spherical, single stranded RNA virus ${ }^{1}$. Prevalence of hepatitis C in Bangladesh is $0.8 \%{ }^{2}$. Approximately 500,000 people succumb each year because of complications of $\mathrm{HCV}$ related chronic liver disease globally ${ }^{3}$. Moreover, a high percentage of chronicity $(\sim 85 \%)$ renders Hepatitis $\mathrm{C}$ a considerable disease burden, with $10-15 \%$ of them leading to cirrhosis of liver in 20 years. Newer Direct Acting Antiviral drugs in the battle against HCV infection have drawn great attention worldwide.

Being a blood-borne virus, it is most commonly transmitted among people who receive improperly screened blood or blood products or via sharing needles among IV drug abusers. Vertical and sexual transmissions are also possible but in a lesser amount.

\section{Clinical course of the Disease:}

$\mathrm{HCV}$ infection is completely asymptomatic in $60-70 \%$ cases despite a chronicity rate of around $85 \%$. 10$15 \%$ of these chronic carriers will develop cirrhosis owing to disease process or various risk factors like alcohol consumption, co-infection with HIV/HBV and other comorbidities ${ }^{4}$. Compensated cirrhosis can progress to decompensation in 5\% patients at 1 year, gradually increasing to $30 \%$ at 10 years from diagnosis. After decompensation 5 year survival rate comes down to $50 \%$ as compared to $91 \%$ in compensated cases $^{5,6}$. Once cirrhosis is established, hepatocellular carcinoma can occur at a rate of $1 \%-4 \%$ a year ${ }^{4}$.

In HBV infection, approximately 5\% develop chronicity $^{7}$ and $10 \%$ of chronic infection ${ }^{8}$ may need treatment. On the other hand, in HCV infection, $85 \%^{8}$ develop chronicity and needs treatment. So, in terms of number of patients need to be treated, the bulk of chronic HCV patients outnumber chronic HBV patients.

\section{Genotype Distribution:}

$\mathrm{HCV}$ infection is variedly distributed throughout the world (fig: 1), with Central Asia and Sub-Saharan Africa hit the most with prevalence of $5.4 \%$ and $5.3 \%$ respectively, with highest prevalent countries are Egypt $(15 \%)$ and Mongolia $(11 \%)^{9}$. Countries of the South East Asia are mostly among the low prevalence countries $(<1 \%)$. The genotypic distribution plays a crucial role in planning management. Although Genotype 1 is most common worldwide, non-genotype $1 \mathrm{HCV}$ cases still comprise over half of all $\mathrm{HCV}$ $\operatorname{cases}^{10}$. Genotype 3 is most prevalent in South Asia, Genotype 4 in Middle East, Egypt and Central Africa and Genotype 5 in South Africa ${ }^{11,12}$.

\section{Treatment Goal:}

The goal of treating HCV is to eliminate the virus and if not possible, to delay its progression to prevent complications. Achievement of Sustained Virological Response (SVR) is considered as protection against progression of the disease and improvement in the clinical outcome. However relapses may occur due to persistence of $\mathrm{HCV}$ in liver or extra-hepatic tissues ${ }^{14}$.

Address of Correspondence: Dr. Salimur Rahman, Professor, Department of Hepatology, Bangabandhu Sheikh Mujib Medical University, Dhaka, Bangladesh

Bangladesh J Medicine 2016; 27 : 74-77 


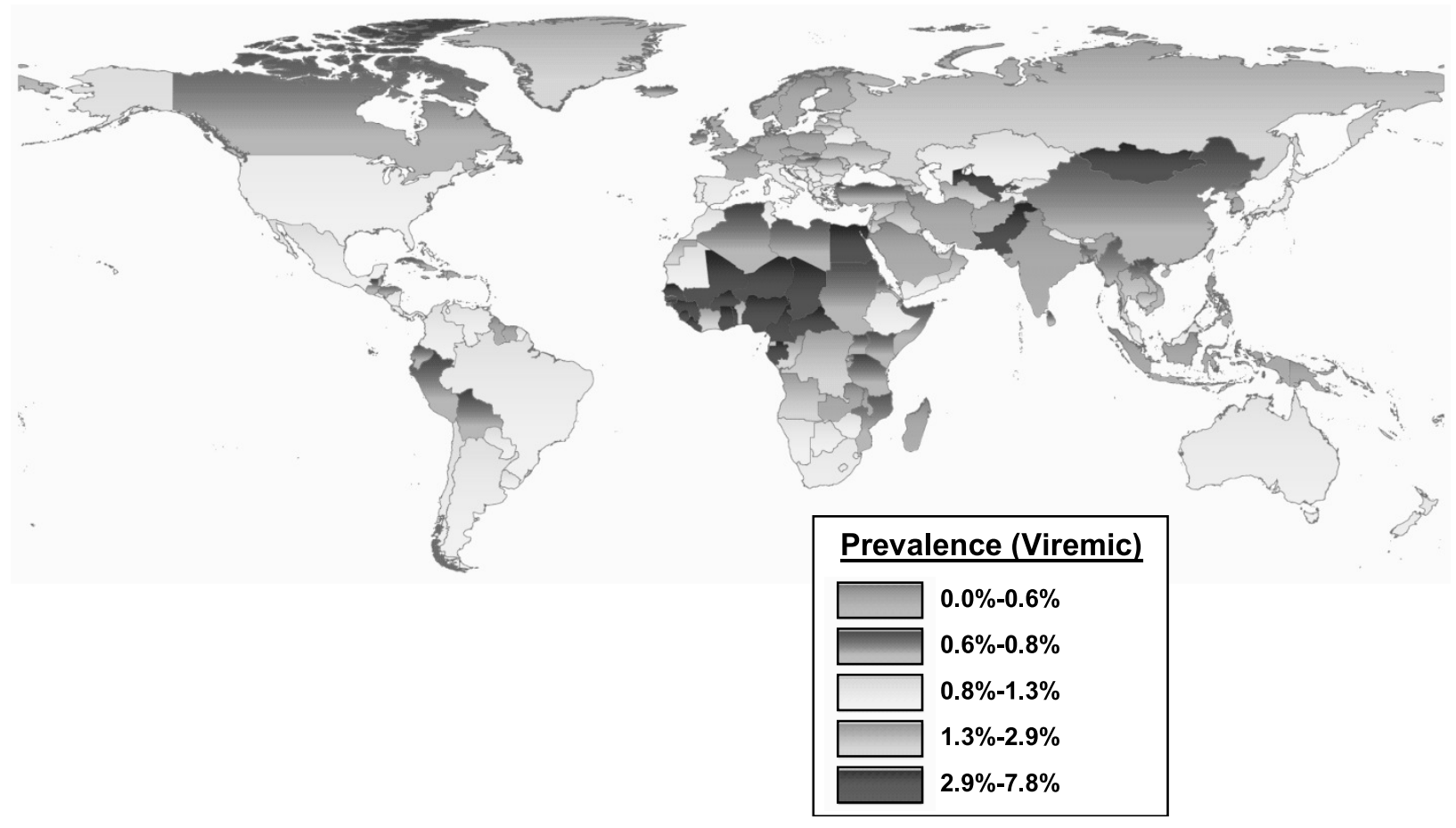

Fig.-1: Global epidemiology of $\mathrm{HCV}$ virus $^{13}$

\section{Evolution of Treatment:}

Since its discovery in 1989, Hepatitis C has been a challenge for the health community. The introduction of Interferon in 1991, addition of Ribavirin in 1998 and pegylation of Interferon in 2001- all these steps have proved to be crucial in HCV management. But they failed to achieve a satisfactory End of Treatment Response (ETR) and Sustained Virologic Response (SVR) in a good number of cases. So discovery of newer and better drugs was needed (fig:2).

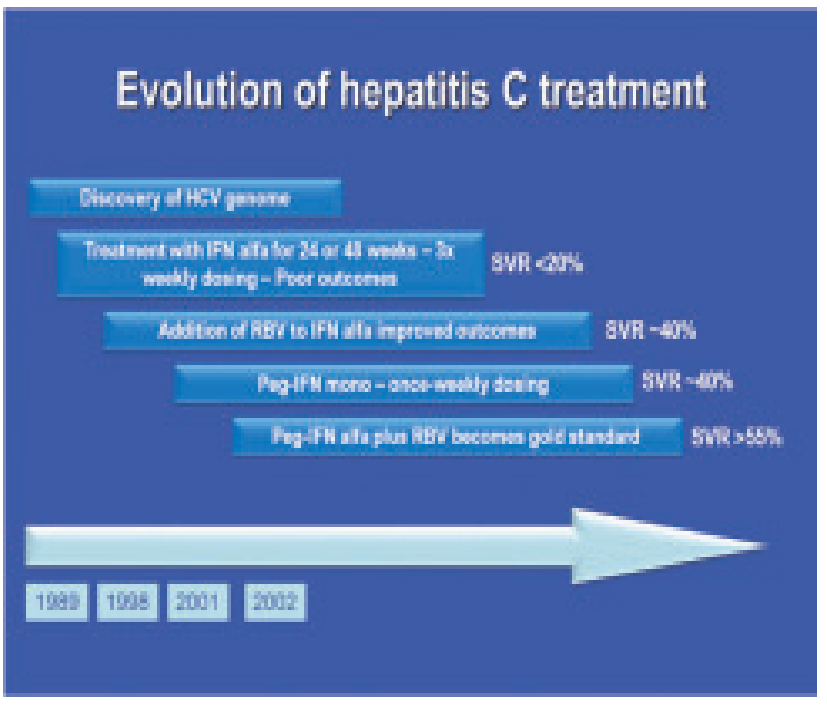

Fig.-2: Evolution of treatment of HCV virus

\section{Direct Acting Antivirals (DAA):}

The breakthrough came in December 2013 when FDA first approved the Direct Acting Antiviral Sofosbuvir. The main targets of the DAAs are viral encoded proteins that are vital for viral replication. There has been a significant breakthrough with the progressive introduction of newer DAAs. The new drugs include Simeprevir, Daclatasvir, Ledipasvir, Ombitasvir, Paritaprevir, Dasabuvir, Elbasvir and Grazoprevir. The initial SVR results with the administration of DAAs are well above the previous benchmark, approaching to $90 \% \&$ above gradually. Treating the special population including patients with decompensated cirrhosis and Hepatocellular carcinoma has also become more feasible than in the Interferon era. A new era is on the rise where Interferon free regimens are now dominating the scenario (fig:3).

\section{Newer DAA:}

The combination of Velpatasvir and Sofosbuvir is well on its way to be approved later this year, as a pangenotype drug, with special affinity towards Genotype $3 \mathrm{HCV}$ infection.

\section{Bangladesh and South Asia:}

In Bangladesh, the results of Sofosbuvir use are promising. The patients who received Sofosbuvir containing regimens since February, 2015, along with Ribavirin and/or Peg-interferon, have mostly cleared 


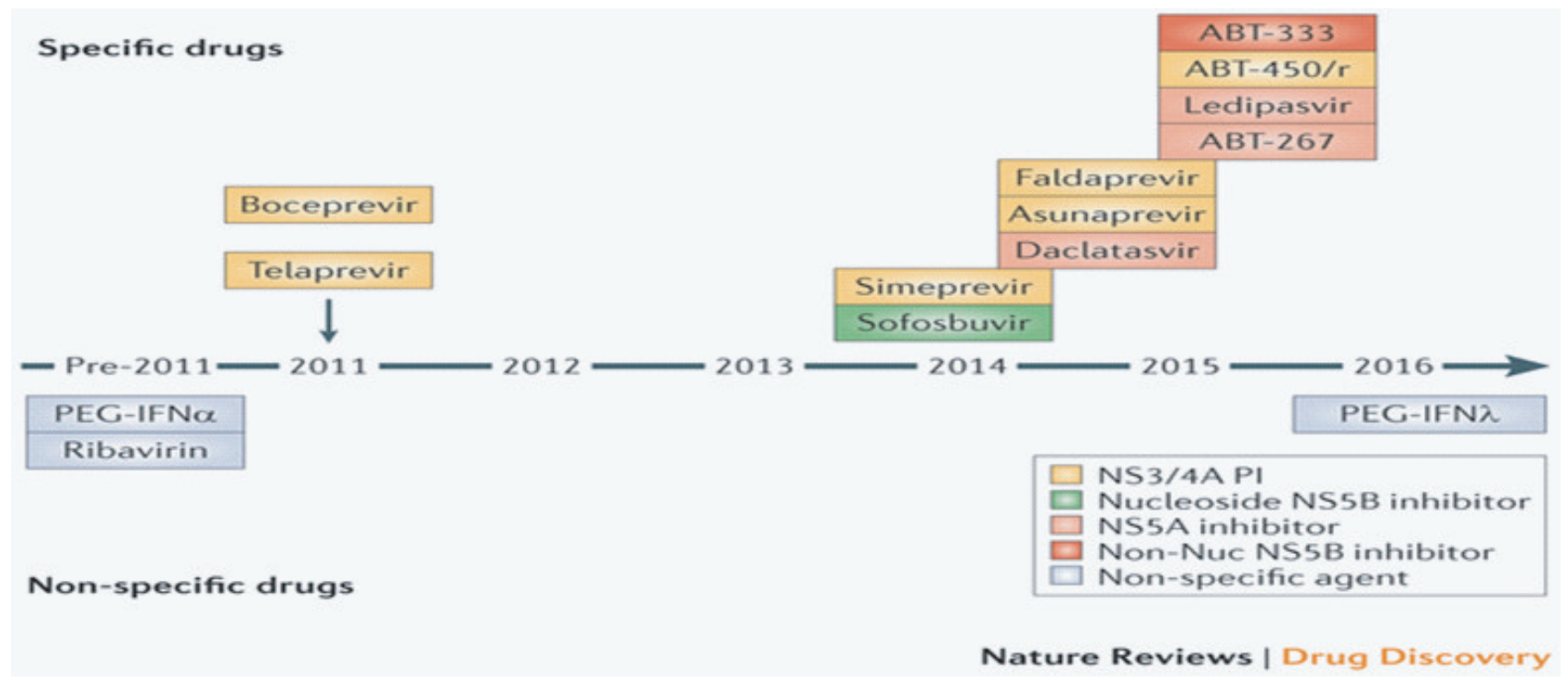

Fig.-3: Evolution of DAAs [15]

HCV and achieved SVR at 24 weeks. The introduction of Daclatasvir since September 2015 has further improved the management, with excellent initial results. With the recent introduction of Ledipasvir, the management of genotype- 1 which is not common in our country, has further improved the situation.

Managing Genotype 3, which is more prevalent in this area and is difficult to treat, is proving to be a challenge [16]. Newer DAAs have overcome this problem. Other special population groups like End Stage Renal Disease with or without maintenance hemodialysis, HCV-HBV and HCV-HIV co-infection are also difficult to treat.

\section{Barriers in access to treatment of $\mathrm{HCV}$ :}

In Bangladesh, majority of $\mathrm{HCV}$ infected patients do not know they are infected due to lack of adequate screening program. Like the west, universal health care is not available here. Comprehensive insurance advantages are also absent. Different strategies to improve these barriers may be taken like identifying high risk groups, creating public awareness, making access to costly drugs, making tests for screening, confirmation, liver fibrosis more available and adequate monitoring .

\section{Prevention:}

Development of vaccine for $\mathrm{HCV}$ is yet not possible due to high genetic variability of the virus including presence of numerous quasispecies, limited animal models for research, difficulty enrolling at-risk people in vaccine trials and lack of a clear marker for protection. So, till now use of disposable syringes and needles, adequate sterilization of instruments, screening of blood and blood products and identification and treatment of carriers is the main mode of prevention.

\section{Cost Considerations:}

The initial high price of the DAAs has been mitigated by the introduction of generic products in developing countries. But the developed counties are still burdened with the same, even after government reimbursements.

\section{Conclusion:}

Due to availability of very effective oral medications with a high sustained virological response, scientists working in this field are hopeful to eradicate HCV infection from the planet in future. DAAs which are pan-genotypic are great hope in the management and eradication of hepatitis C. Properly addressing the global burden with appropriate management to combat $\mathrm{HCV}$ infection surely mark great advancement towards a newer and better future.

\section{References:}

1. MohdHanafiah K, Groeger J, Flaxman AD, Wiersma ST. Global epidemiology of hepatitis $\mathrm{C}$ virus infection: new estimates of age-specificantibody to $\mathrm{HCV}$ seroprevalence. HEPATOLOGY 2013;57:1333-1342.

2. Mamun-Al-Mahtab, Salimur Rahman, Fazal Karim, Graham Foster, Susannah Solaiman. Epidemiology of Hepatitis C Virus in Bangladeshi General Population. BSMMU J 2009; 2(1):23-6.

3. Lozano R, Naghavi M, Foreman K, Lim S, Shibuya $\mathrm{K}$, Aboyans V, Abraham J, et al. Global and regional mortality from 235 causes of death for 20 age groups 
in 1990 and 2010: a systematic analysis for the Global Burden of Disease Study 2010. Lancet 2012;380:2095-2128

4. Chen SL, Morgan TR. The Natural History of Hepatitis C Virus (HCV) Infection. Int $\mathrm{J}$ Med Sci 2006; 3(2):47-52. doi:10.7150/ijms.3.47. Available from http://www.medsci.org/v03p0047.htm

5. Fattovich G. et al. Morbidity and mortality in compensated cirrhosis type C: a retrospective followup study of 384 patients. Gastroenterology. 1997 ;112(2):463-72

6. Serfaty L. et al. Determinants of outcome of compensated hepatitis C virus-related cirrhosis. Hepatology.1998;27(5):1435-40

7. Kenneth C. Hyams, Risks of Chronicity Following Acute Hepatitis B Virus Infection: A Review, Clin Infect Dis, 1995, 20 (4): 992-1000.

8. Hepatitis B virus, Feldman M, Friedman L, Brandt L J (eds) 2015, Sleisenger and Fordtran's gastrointestinal and liver disease, Saunders, Philadelphia.

9. Gower E, Estes C, Blach S, Razavi-Shearer K, Razavi H. Global epidemiology and genotype distribution of the hepatitis C virus infection. J Hepatol. 2014;61(1 Suppl):S45-57.

10. Messina JP1, Humphreys I, Flaxman A, Brown A, Cooke GS, Pybus OG, Barnes E.Global distribution and prevalence of hepatitis $\mathrm{C}$ virus genotypes. Hepatology. 2015 Jan;61(1):77-87. doi: 10.1002/ hep.27259. Epub 2014 Jul 28.

11. Recommendations for prevention and control of hepatitis $\mathrm{C}$ virus (HCV) infection and HCV-related chronic disease. Centers for Disease Control and Prevention. MMWR Recomm Rep. 1998 Oct 16; 47(RR-19): 1-39.

12. Hepatitis $\mathrm{C}$ virus infection in African Americans. Pearlman BL Clin Infect Dis. 2006 Jan 1; 42(1): 82-91

13. Shire N J, Sherman K E, Epidemiology of Hepatitis C Virus, A Battle on New Frontiers, Gastroenterol Clin N Am 44 (2015) 699-716.

14. Bruno S, Stroffolini T, Colombo M, Bollani S, Benvegnù L, Mazzella G, Ascione A, Santantonio T, Piccinino F, Andreone P, et al. Sustained virological response to interferon-alpha is associated with improved outcome in HCV-related cirrhosis: a retrospective study. Hepatology. 2007;45:579-587.

15. Manns M P, Hahn T V, Novel therapies for hepatitis $\mathrm{C}-$ one pill fits all?, Nature Reviews Drug Discovery 12, 595-610,(2013).

16. Tapper EB, Afdhal NH. Is 3 the new 1: perspectives on virology, natural history and treatment for hepatitis C genotype 3. J Viral Hepat 2013; 20: 669-77. 